\author{
FRANCISCO MONTES GONZÁLEZ \\ UNIVERSIDAD DE GRANADA
}

\title{
Una guadalupana inédita de Juan Correa en el convento de San José del Carmen de Sevilla
}

$\mathrm{E}$ l culto a la Virgen de Guadalupe de México arraigó en la feligresía sevillana durante el último tercio del siglo XVII. La principal vía de difusión peninsular de esta devoción americana fue la remisión, por parte de los indianos, de numerosas copias de la imagen, desde el Tepeyac a sus lugares de origen, bien como un símbolo de agradecimiento por la fortuna alcanzada o como un acto de religiosidad pública. ${ }^{\mathrm{I}}$ La vinculación comercial de Sevilla y Cádiz con la Carrera de Indias propició que ambas ciudades se convirtiesen en los puntos geográficos adonde llegó el mayor número de estas imágenes, favoreciendo con ello un rápido auge devocional. En el grado de aceptación que alcanzó la representación de la Virgen de Guadalupe desempeñó un papel fundamental el hecho de que los lienzos y cobres recogiesen la "fiel copia" de la imagen, plasmada en la capa del indio Juan Diego, razón por la cual se le atribuían propiedades milagrosas, sobre todo si venían "tocadas al sagrado original” y con una inscripción que así lo certificara. Además, las similitudes iconográficas de esta Virgen india con la multitud de "Inmaculadas" proliferantes en el panorama religioso andaluz harían que no se convirtiese en un objeto extraño a ojos de los devotos,

I. En su estudio sobre el comercio artístico entre España y América, García Sáiz señala que "la mayoría de estas obras — religiosas — son enviadas desde y no reclamadas por" los devotos peninsulares. María Concepción García Sáiz, "Arte colonial mexicano en España”, Artes de México, núm. 22, I993-I994, p. 26. 
sino en una pieza venerada casi como un amuleto ante las continuas adversidades de la sociedad barroca. ${ }^{2}$

En el extenso repertorio de imágenes guadalupanas conservadas en recintos religiosos y en colecciones particulares sevillanas figuran realizaciones de los principales pintores de la escuela novohispana, así como ejemplos de distintas tipologías en cuanto a los modelos iconográficos y los materiales empleados para su realización. ${ }^{3}$ El estudio de estas obras lo realizó exclusivamente el historiador local Joaquín González Moreno. En sus investigaciones llegó a catalogar cerca de 400 guadalupanas repartidas por toda Andalucía y sacó a la luz abundantes noticias sobre el fervor hacia la imagen mexicana en la región. ${ }^{4}$ En las últimas décadas, otros estudios se han dedicado a destacar la presencia de estos iconos repartidos por todo el ámbito peninsular, ya sea mediante catálogos de objetos americanos o en aportaciones exclusivas acerca de su temática y función. 5

Uno de los máximos exponentes del gremio de pintores novohispanos en las últimas décadas del siglo Xvir fue el mulato Juan Correa. La relación del artista con la tilma sagrada del indio Juan Diego iría más allá de su intervención como mero copista, al ser uno de los primeros maestros encargados de examinar el soporte original para obtener de él una copia en papel aceitado. ${ }^{6}$

2. Diversos investigadores han apuntado que se trata de una "trascripción moderna de la Virgen apocalíptica", teniendo como único rasgo de exotismo las facciones indias de su rostro. Manuel Trens, María. Iconografía de la Virgen en el arte español, Madrid, Plus-Ultra, I974, pp. 68-7 I.

3. En cuanto a la vinculación con la capital hispalense, véase Francisco Montes González, "Sevilla y la Virgen de Guadalupe. El camino de lo devocional y lo artístico", en Joan Feliú et al., Caminos encontrados. Itinerarios históricos, culturales y comerciales en América Latina, Castelló de la Plana, Universitat Jaume I, 2009.

4. Joaquín González Moreno, Iconografía guadalupana, México, Jus, t. I, I959, t. II, I974. Hay una edición actualizada que compendia ambos volúmenes: Joaquín González Moreno, Iconografía guadalupana en Andalucía, Sevilla, Consejería de Cultura-Junta de Andalucía, I99 I. Además de estos volúmenes debe señalarse que el autor publicó una veintena de artículos sobre este tema en la prensa local sevillana.

5. Véanse entre otros Jaime Cuadriello,"La propagación de las devociones novohispanas: las guadalupanas y otras imágenes preferentes”, en María Luisa Sabau García (dir.), México en el mundo de las colecciones de arte, Nueva España II, México, Universidad de Colima, I994, pp. 257-289; Patricia Barea Azacón, "La iconografía de la Virgen de Guadalupe en España”, Archivo Español de Arte, núm. 3 18, 2007, pp. I77-206.

6. De este hecho da testimonio Miguel Cabrera en su Maravilla americana según palabras de José de Ibarra: "Le tomó perfil a la misma imagen original [...] en papel azeytado del tamaño de la misma Señora, con el apunte de todos sus contornos, trazos y números de Estrellas, y de 
Este hecho motivó que sus realizaciones alcanzasen un significado especial, pues tendrían asociado un mayor contenido taumatúrgico dada la vinculación física con el objeto milagroso. Numerosos autores han afirmado que Correa fue el artista guadalupano más prolífico de su época y que sus representaciones eran "las más apreciadas por su fidelidad y perfección"? Del mismo modo, este maestro fue el encargado de establecer el modelo iconográfico tradicional que luego repetirían sus continuadores. En este esquema, la efigie de la Virgen aparecía enmarcada por cuatro cartelas que presentaban de forma tetraepisódica los hechos aparicionistas del indio Juan Diego, a la que se sumaba una última en la parte inferior con la descripción del paisaje del Tepeyac junto a los monumentos erigidos en aquellos lugares. Finalmente, en algunas ocasiones rodeaba a la Virgen una guirnalda de flores, que simbolizaba tanto aquéllas depositadas por los indios a modo de ofrendas, como el elemento milagroso causante del calco mariano. A éstas se añadiría en interpretaciones más tardías una serie de angelotes, atlantes y tenantes de los objetos alegóricos recogidos en las letanías lauretanas.

En el catálogo de González Moreno se encuentran inventariados en Sevilla seis lienzos firmados por Juan Correa. ${ }^{8}$ Esta serie comprende modelos que van desde la típica composición aludida — como los de la capilla de San Onofre y el convento de San Leandro- - pasando por el ejemplo del convento de Santa Paula - que representa únicamente a la Virgen con una inscripción en la parte inferior referida a su encargo por parte de los duques de Alburquerque-, hasta otros dos en colecciones particulares de los cuales se desconocen su tipología y paradero actual.9 Sin embargo, el mejor exponente de la iconografía guadalupana creada por Correa es el lienzo que se conserva en la capilla de la Hermandad Sacramental de la iglesia de San Nicolás de Bari, fechado

rayos; y de este dicho perfil se ha difundido muchos, de los que se han valido y se valen hasta hoy todos los artífices". Miguel Cabrera, Maravilla americana..., México, Imprenta del Real y Más Antiguo Colegio de San Ildefonso, I756, p. Io; apud Jaime Cuadriello, "La propagación de las devociones novohispanas...", op. cit., p. 268.

7. Fidel de Jesús Chauvet et al., Álbum del 450 aniversario de las apariciones de Nuestra Señora de Guadalupe, México, Buena Nueva, I98 I, p. I34.

8. Joaquín González Moreno, Iconografía guadalupana en Andalucía, op. cit., pp. 74-75.

9. La inscripción de la Guadalupana de Santa Paula dice: "En 30 de noviembre de I 7 I 2 años se tocó con su sagrado original hallándose presentes los Excmo. Señores duques de Alburquerque, para quienes se abrió la vidriera a las diez de la noche". 
en $1704 .{ }^{\text {Io }}$ En el cuadro se dispone la composición de forma horizontal, destacando la profusión del colorido adorno floral que rodea a la Virgen, los angelotes que sustentan las cuatro cartelas y el delicado trazo en el dibujo de la guadalupana. ${ }^{\text {II }}$ Otro aspecto más que percibe Jaime Cuadriello en la imagen es su luminosidad, cuyo fin no es otro que "transmitir en verdad la idea de un portento mariofánico”. ${ }^{12}$ La procedencia de esta obra es una incógnita, aunque todas las hipótesis hablan de un patrocinio excepcional que establece como su origen la donación de algún indiano, miembro de dicha corporación religiosa o su pertenencia al convento de San Agustín, de donde llegaría tras las desamortizaciones decimonónicas.

De la selección publicada por González Moreno se sirvieron Vargaslugo y Victoria para completar el capítulo correspondiente al repertorio guadalupano en su extenso volumen sobre la obra pictórica de Correa. ${ }^{13} \mathrm{~A}$ las piezas aludidas en la provincia de Sevilla añadirían otras localizadas en colecciones particulares, así como un lienzo que se conserva en el palacio de los Marqueses de Villadarias en Antequera, el cual podría estar relacionado con la magnífica serie sobre la vida de la Virgen del mismo artista depositada en el Museo $\mathrm{Mu}$ nicipal de esta localidad malagueña. ${ }^{\mathrm{I}}{ }^{2}$ Entre el resto de imágenes de Correa documentadas en España por los autores, cabría destacar el primer lienzo en la cronología del pintor, consignado por Veytia en I746. ${ }^{\text {I5 }}$ Se trata de un encargo realizado en 1667 para el monasterio de San Francisco de Valladolid en homenaje al obispo Juan de Zumárraga, el cual recoge de forma sintética los cinco

Io. En sus primeros catálogos, González Moreno no acertó a localizar la firma de Correa, la cual descubrieron posteriormente otros investigadores sevillanos bajo la moldura del marco en la década de los ochenta. Alfredo Morales et al., Guia artística de Sevilla y su provincia, Sevilla, Excma. Diputación Provincial de Sevilla, I98 I, p. 91.

I I. Véase la ficha de la obra en el catálogo de la exposición Los Siglos de Oro de los virreinatos americanos, Madrid, Sociedad Estatal para la Conmemoración de los Centenarios de Felipe II y Carlos V, I999, pp. 306-309, cat. 86.

I 2. También resalta el hecho de que la mandorla se encuentre cerrada formando una aureola completa de nubes. Jaime Cuadriello, "La propagación de las devociones novohispanas...", $o p$. cit., p. 272.

I 3. Elisa Vargaslugo y José G. Victoria, Juan Correa. Su vida y su obra, México, Universidad Nacional Autónoma de México-Instituto de Investigaciones Estéticas, I985, vol. II, t. I, pp. 238-250.

I 4. Ibidem, pp. 68-85; José Luis Romero Torres, Tota Pulcra, Málaga, Obispado de Málaga, 2005, p. 202 (catálogo de la exposición).

I 5. Mariano Fernández de Echeverría y Veytia, "Baluartes de México", ms. original, I746, f. 48r; apud Vargaslugo y Victoria, op. cit., vol. II, t. II, p. 443. 
pasajes de la aparición narrados por Becerra Tanco en su volumen del año anterior. Tras numerosos esfuerzos para localizarlo, finalmente el cuadro pudo ser expuesto y estudiado con detenimiento para la exposición americana conmemorativa de los centenarios de Carlos V y Felipe II. ${ }^{16}$ Además de esta variedad de piezas aludidas, Cuadriello reseñó en un estudio posterior cuatro lienzos autógrafos de Correa dispersos por la Península, que representaban únicamente a la efigie mariana en su calco original, despojada de cualquier elemento decorativo. ${ }^{17}$

El hallazgo de la firma de Juan Correa en una pintura de enorme atractivo de la iglesia conventual de las carmelitas descalzas de Sevilla supone un aporte de relevancia a la extensa producción guadalupana del pintor mexicano. ${ }^{18}$ La tipología de este lienzo responde a la composición clásica antes descrita, que proliferó de forma abundante en el comercio artístico transatlántico durante el primer tercio del siglo xviII. Sin embargo, en esta obra, aparte de la magnífica interpretación de los modelos figurativos de las escenas, nada comunes en cuanto a la perfección de sus diseños, sorprenden las innovaciones iconográficas introducidas en unas tarjas de tamaño excepcional respecto al normalizado. De todas las obras documentadas del pintor, estas escenas pueden considerarse únicas en su género, no sólo por el elaborado dibujo de la composición tetraepisódica sino por la cantidad de singularidades que ofrecen en su contenido. A simple vista, hay que partir de la base de que Correa aprovechó los grabados de Matías de Arteaga para la edición sevillana de I685 de la Felicidad de México de Becerra y Tanco, siendo la proliferación de ángeles músicos y custodios la que aquí delata su empleo como fuente iconográfica. ${ }^{19}$ Además de esta matización, el lienzo plantea la necesidad de realizar un

I6. Veáse la ficha en Los Siglos de Oro de los virreinatos americanos, op. cit., pp. 306-309, cat. 85. Actualmente el lienzo se conserva en el Museo Nacional de Escultura de Valladolid.

I7. Cuadriello, "La propagación de las devociones novohispanas...", op. cit., pp. 268-269.

I 8. La inscripción "Correa f." se esconde bajo la moldura del marco en la parte inferior del lienzo.

19. La edición impresa por Tomás López de Haro fue la tercera que se hizo tras las dos ediciones mexicanas de I 666 y I 675. El primer investigador en percatarse de la existencia de dichas estampas fue Jaime Cuadriello en su Maravilla americana. Variantes de la iconografía guadalupana. Siglos XVII-XIX, México, Patrimonio Cultural de Occidente, I989, p. 47. Para un estudio más detallado de las mismas véase Jaime Cuadriello, "Visiones de Guadalupe", Artes de México, núm. 29, I995, p. 27. Posteriormente han aparecido otros estudios recalcando la importancia de estas estampas sevillanas para la iconografía guadalupana. Véase el más reciente sobre la sillería de la colegiata de Guadalupe: Nelly Sigaut, Guadalupe, arte y liturgia. La sillería de coro de la colegiata, México, El Colegio de Michoacán, 2006. 
análisis exhaustivo de algunas particularidades para poner de relieve su calidad, igualable en maestría a la conservada en la iglesia de San Nicolás de Bari, pero única en el extenso campo de las realizaciones guadalupanas. A pesar de no haber descubierto la autoría de la obra, González Moreno ya se había percatado de la singularidad de este lienzo "anónimo" al dedicarle en su estudio varias alusiones que la distinguían de otros modelos:

Donde más se acusa la nueva interpretación del pasaje del Tepeyac es en la reproducción propiedad del convento de Santa Teresa de Sevilla: en ella una legión de serafines y querubines inunda las tres primeras cartelas, muchos de ellos con arpas y violas en las manos, que evocan el celestial concierto que Juan Diego escuchó antes de contemplar la sublime aparición. ${ }^{20}$

Entre los valores de esta pintura cabe destacar la descripción de la figura de la Virgen, en la que una vez más queda patente la superioridad de Correa en su interpretación. Su rostro con los ojos entornados la sitúan en el grupo de las coloquialmente llamadas "dormilonas". La perfección del trazo denota un calco exacto del original, tanto en el conjunto mariano como en el ángel que la sostiene, de cuyas propiedades ya se hiciesen eco en la época, como se ha visto en el testimonio que da José Ibarra a Miguel Cabrera. Un aspecto sorprendente a simple vista es la luminosidad que irradia el modelo, bien sea por la claridad en el cromatismo o por el juego óptico empleado para diseñar las ráfagas, graduando con intermitencias en intensidad los tonos dorados de la aureola. De este modo, la Guadalupana se convierte en un auténtico fulgor divino que inunda el espíritu de los fieles y sorprende por su belleza plástica.

En la cartela de la esquina superior izquierda aparece descrito el momento de la primera aparición de la Virgen al indio Juan Diego en el paraje del Tepeyac. El característico esquema compositivo se ha invertido para colocar al indio en el lado derecho acompañado de una corte angelical, de la que dos miembros sentados en primer plano sobre unas rocas aparecen como testigos. A este grupo se suma la nota más llamativa de la escena, la representación de la bandada de pájaros, siguiendo el relato descrito por el indio Valeriano en el Nican Mopohua, en el que la música celestial de unas aves exóticas sirvió para 


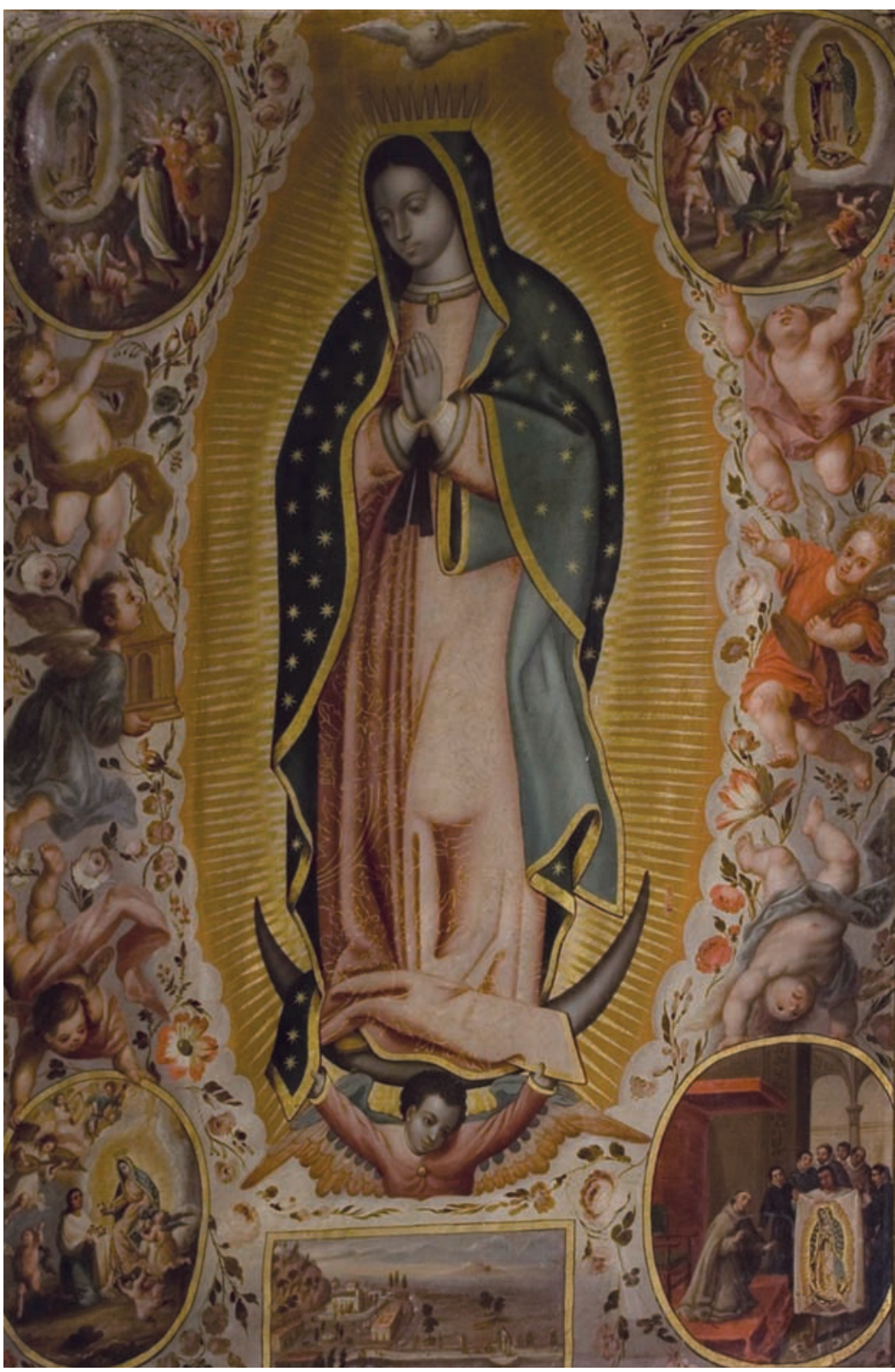

I. Juan Correa, Virgen de Guadalupe, ca. I685-1695. Convento de San José del Carmen, Sevilla. Foto: Francisco Montes. 
que el indio Juan Diego acudiese al llamado de la Virgen. ${ }^{21}$ El propio González Moreno resaltaría este detalle, afirmando que no volverá a repetirse en ninguna de las realizaciones existentes en la península. ${ }^{22}$

La segunda cartela, situada a la derecha de la anterior, describe el momento en que Juan Diego huye del encuentro de la Virgen para acudir en busca de un médico que atienda a su tío enfermo. En la escena se introducen como novedades la presencia de un coro de ángeles músicos en la esquina superior y la figura de la Virgen, que se desprende de su característico hieratismo y abre los brazos para calmar el sobresalto del indio. Junto a éste aparecen otros ángeles custodios que intervienen con diferentes gestos indicativos, haciendo más dinámica y participativa la historia al espectador. En la composición sorprende la colocación de un pequeño ángel en un complicado escorzo, que se arrodilla para denotar el asombro y aturdimiento que le causa la presencia de la Virgen.

Algunas de las singularidades más llamativas introducidas por Correa aparecen en la cartela del tercer episodio que ocupa el ángulo inferior izquierdo, donde se narra el momento del ofrecimiento de las rosas a la Virgen para que las convierta en el objeto milagroso de la estampación. En la mayoría de las representaciones, la Virgen figura de pie, en postura mayestática, para poco a poco ir rompiendo el plano frontal al adelantar un brazo con el que ofrece a Juan Diego un ramillete de las flores milagrosas. Sin embargo, en esta pintura del convento de San José, la Virgen aparece sedente en un trono de nubes, tomando las flores de la ofrenda realizada por un ángel que se colo-

2I. En una traducción hecha por monseñor José Luis Guerrero Rosado, queda descrito este pasaje con las siguientes líneas: "6.- Era sábado, muy de madrugada, lo movía su interés por Dios [respondiendo a] su insistente llamada. 7.- Y cuando vino a llegar al costado del cerrito, en el sitio llamado Tepeyac, despuntaba ya el alba. 8.- Oyó claramente sobre el cerrito cantar, como cantan diversos pájaros preciosos. Al interrumpir su gorjeo, como que les coreaba el cerro, sobremanera suave, agradabilísimo, su trino sobrepujaba al del coyoltótotl y del tzinitzcan y al de otras preciosas aves canoras. 9.- Se detuvo a ver Juan Diego. Se dijo: ¿’Por ventura es mi mérito, mi merecimiento lo que ahora oigo? ¿Quizá solamente estoy soñando? ¿Acaso estoy dormido y sólo me lo estoy imaginando? Io.- ¿Dónde estoy? ¿Dónde me veo? ¿Acaso ya en el sitio del que siempre nos hablaron los ancianos, nuestros antepasados, todos nuestros abuelos: en su tierra florida, en su tierra de nuestro sustento, en su patria celestial? I I.- Tenía fija la mirada en la cumbre del cerrito, hacia el rumbo por donde sale el sol, porque desde allí algo hacía prorrumpir el maravilloso canto celestial. I 2.-Y tan pronto como cesó el canto, cuando todo quedó en calma, entonces oye que lo llaman de arriba del cerrito, le convocan: Mi Juanito, mi Juan Dieguito", http://www.virgendeguadalupe.org.mx/apariciones/.

22. González Moreno, Iconografía guadalupana en Andalucía, op. cit., p. 20. 
ca a su izquierda, mientras es llevada por el característico querubín transformado en un angelillo atlante. Además, se vuelve a repetir el coro de ángeles músicos, aunque con la novedad de que uno de ellos se coloca en el plano terrenal portando la partitura que sus compañeros celestiales interpretan ante la Virgen y el indio. También González Moreno resaltó la maestría del artista en la ejecución de este paisaje, sólo que equivocando la partitura de música con los instrumentos de pintor e intuyendo un cuestionado reflejo de la escuela sevillana:

Destaca entre todos estos medallones el tercero, donde la Virgen sedente, pone en manos del indio un hermoso ramillete de rosas. Alrededor de la imagen revolotean ángeles con instrumentos y dos de ellos con pincel y paleta, cuya factura y colorido pregonan que ha sido influenciado por los talleres sevillanos de aquella época. ${ }^{23}$

Por ello, el resultado es un esquema compositivo sorprendente e inédito hasta ahora en la tradición pictórica guadalupana, propio de un barroquismo tardío que se adelanta en esta realización.

Como es característico, el cuarto óvalo representa el momento solemne del descubrimiento de la imagen guadalupana a ojos del obispo Zumárraga en el salón del trono del palacio episcopal. Los intérpretes de la historia mariana representaron en esta escena a los personajes señalados por los relatos literarios siguiendo el modelo de una de las primeras estampas impresas para la publicación del volumen del bachiller Miguel Sánchez en I684. ${ }^{24}$ Junto al prelado, se cree que fueron testigos de la aparición el clérigo Juan González y algunos criados y familiares. Sin embargo, en esta composición aparecen al fondo dos personajes de piel oscura cuyos gestos reflejan ciertas peculiaridades. Una de las hipótesis que lleva a plantear este conjunto es que el joven de rasgos negroides, que mira directamente al espectador reclamando su atención, despistado del relevante acontecimiento que se está produciendo, fuese el propio Correa, quien con este gesto quisiera dejar testimoniada su autoría en una de sus obras maestras. Por otro lado, podría entenderse el deseo del pintor por aparecer dignificado en su trabajo, cual Velázquez novohispano que huye de

23. Ibidem, pp. 19-20.

24. La estampa sirvió para ilustrar el libro Imagen de la Virgen María Madre de Dios de Guadalupe, del bachiller Miguel Sánchez, impreso en I648 por la viuda de Bernardo Calderón. Elisa Vargaslugo, "Iconología guadalupana", en Imágenes guadalupanas, México, Centro Cultural/Arte Contemporáneo, 1987, p. 67, lám. 39 (catálogo de la exposición). 


\section{8}

FRANCISCO MONTES GONZÁLEZ

la desconsideración gremial, para el que habría sido "elegido" por la propia divinidad presente en aquel momento. ${ }^{25}$ Desde este enfoque, dicho discurso podría aceptarse como lógico, pues no sería coherente intuir dichas reivindicaciones intelectuales en los círculos artísticos novohispanos hasta la llegada de Cabrera, y aún más, si lo consideráramos en un esquema de valoración sería más afín con su papel de apóstol guadalupano, que mediante el envío de estas estampas fuera de las fronteras americanas participa como un misionero en el arraigo devocional. Por otro lado, también sería cuestionable si el anciano que se adelanta al anterior personaje, con aspecto mestizo y el rostro cabizbajo, pudiera ser una figuración anacrónica del tío Juan Bernardino, a quien según los relatos se apareció la Virgen para sanarlo en el mismo instante del descubrimiento de la tilma en el salón episcopal. De esta forma quedaría sintetizada la historia aparicionista completamente, pues en otros modelos esta escena se colocaba en la parte inferior sustituyendo la del paisaje del Tepeyac.

Finalmente, la última de las cartelas, al centro de la zona inferior del lienzo, describe la vista del cerro del Tepeyac, presidido en un primer plano por la primitiva ermita, anterior al santuario dedicado en I709. Una de las peculiaridades distintivas de los paisajes descritos por Correa es la visión panorámica de un conjunto donde destaca llamativamente la disposición protagónica de la calzada. Este camino, que comunicaba la villa de Guadalupe con la ciudad, fue adecentado con las mandas del arzobispo fray Payo Enríquez de Ribera, colocando una serie de monumentos de los misterios del Rosario, para que de este modo los visitantes fueran realizando cada una de las estaciones en su peregrinación. ${ }^{26}$ Esta escena es uno de los elementos de que se sirven los

25. Acerca de la importancia del artista como pintor guadalupano, véase Elisa Vargaslugo, "El pintor que tenía 'el don...'”, Anales del Instituto de Investigaciones Estéticas, vol. XXVII, núm. 86,2005 , pp. 203-21 5 .

26. El propio Florencia, en su Estrella del Norte, exaltaría varias veces la labor del prelado sevillano como benefactor de la devoción mariana: "Ya apunté lo que deseó el Ilusstrisimo y Excelentissimo Señor D. Fr. Payo de Ribera adelantar, y promover el culto de la Señora y su Santuario. A este fin hizo la Calçada desde Mexico hasta la puente de Guadalupe, tan costosa y acomodada, y trajo el agua hasta la plaza del Santuario, fabrico en ella hasta una muy buena pila, en que se recoge. Cuando hubiera hecho mas habia hecho mucho, y por esto solo mereceria contarse entre los muy insignes bienhechores del Santuario". Francisco de Florencia, La Estrella del Norte de México..., México, María de Benavides, viuda de Juan de Ribera, I688, p. I87v. Acerca de la calzada y las capillas del Rosario, ibidem, pp. $25 \mathrm{r}-25 \mathrm{v}$. Véanse algunos datos más sobre la vinculación de este personaje con la Virgen de Guadalupe en Francisco Montes González, "Los Enríquez de Ribera. Ilustres sevillanos guadalupanos", Boletín Guadalupano, núm. 67, 2006, pp. I4-I6. 
investigadores a la hora de datar los lienzos, ya que la presencia del antiguo o el nuevo templo, así como de la calzada, ayuda a encuadrarlos en un periodo concreto. Por tanto, este lienzo de la clausura sevillana debió ejecutarse entre I685 y 1695, fechas que trascienden desde la remodelación de la calzada, la publicación de los grabados de Arteaga y el derribo del primitivo templo.

En cuanto a los ángeles que rodean la sagrada imagen, se aprecian las particularidades del diseño de Correa al dibujarlos panzones y con rostros de extraña belleza. La similitud con los modelos del lienzo de San Nicolás es evidente, aunque en este caso, además de aparecer como atlantes de las cartelas, dos de ellos pasan a portar sendos objetos alegóricos de las letanías lauretanas, ofreciendo sus movimientos y el vuelo de los paños un efecto de dinamismo mucho mayor. En ambas pinturas asoman los rasgos estéticos empleados por Correa en el dibujo de estas criaturas celestiales. La misma posición de estos seres aparece en un lienzo anónimo de menor factura en el Museo de la Basílica de Guadalupe de México. ${ }^{27}$ Dos últimos detalles a consignar en este análisis iconográfico corresponden a la característica guirnalda de flores con pajarillos que rodea a la efigie y la paloma del Espíritu Santo que en la parte superior corona a la Virgen como Reina celestial.

Algunas de las dificultades más comunes que encuentran los estudiosos guadalupanos son la datación de la obra y el contexto de su realización. La proliferación del icono llevó a gran número de artistas mexicanos a dedicarse a la exportación de estas piezas, hecho que reflejan los cuantiosos registros de navíos donde se anotaron "caxas con láminas de Nuestra de Señora de Guadalupe de México". Si a este fenómeno añadimos que otras tantas de estas imágenes llegaron como parte de los bienes de algún difunto o en la dote de las religiosas que ingresaban en estas clausuras, la incógnita sobre su recepción peninsular se convierte en una tarea difícil de resolver. En el caso de esta obra inédita de Correa, su trayectoria puede documentarse en parte gracias al hallazgo del expediente de donación de un particular al convento de las religiosas carmelitas, aunque permanece aún el enigma sobre la identidad del comitente y el lugar primitivo a su llegada a la capital hispalense. Dado el valor artístico de la pieza, debió de ser el encargo de un personaje relevante del gobierno civil o eclesiástico novohispano, pudiendo corresponder al mecenazgo en la figura del virrey-arzobispo fray Payo Enríquez de Ribera si las evidencias estilísticas no reflejaran la utilización de las estampas de Arteaga impresas en 1685 ,

27. Cuadriello, Maravilla americana..., op. cit., p. 46. 
un par de años después del fallecimiento del prelado agustino. La existencia del lienzo en esta clausura se conoció gracias a la localización de su expediente de ingreso en los bienes que sacó a la luz María Luisa Cano en su monografía sobre el conjunto conventual. ${ }^{28}$ En el texto, la superiora de la comunidad daba fe del obsequio recibido con fecha 3 de noviembre de 1804 mediante el siguiente escrito:

Digo yo María de la Paz. Priora de este Convento de Carmelitas / Descalzas de Sevilla que tengo en la Iglesia de Nuestro Convento / un Quadro de la Imagen de N. Sra. de Guadalupe, con Moldu / ra Dorada, de tres [...], y dos escasas de / ancho y lo recibí de mi Sra. Da Ana Gabriela White, alias Blan / co, que lo dio para que se le diese culto a la Imagen; era dicho / Quadro de Dn. Guillermo Lathelise, de nación Francés, el / que teniendo que irse a Francia con su familia, lo dexó en / casa de su Comadre $\mathrm{D}^{a}$ Micaela Aguilar para que se lo / vendiera, y no aviendo encontrado comprador, y aviendo / ella desvaratado su casa, lo puso en la de mi Sra. Da / Ana White, alias Blanco, esta Sra. lo puso en mi Convento / y para que conste en todo tiempo firmo este instrumento en / este sobre: dicho Convento de Sevilla en 3 días del mes de Noviembre de I 804. Ma. de la Paz Priora. ${ }^{29}$

A través de esta información consta como propietario un caballero francés afincado en Sevilla, de nombre Guillermo Lathelise, quien debido a los convulsos momentos políticos que se vivían durante esos años en España debió huir a su patria, no sin antes legar el cuadro a su comadre y ésta, finalmente, también por causas de una mudanza, a la donante Ana White, tía paterna y madrina del afamado escritor, el cual gozó de gran reputación en los círculos intelectuales de la época. ${ }^{30}$ Con estos datos es difícil dilucidar si el lienzo llegó a dicho propietario mediante compra a algún particular, en el expolio de un recinto religioso o en la herencia de algún antepasado, ya que habrían transcurrido cerca de 120 años desde su realización. Un hecho que pudiera ser significativo y

28. María Luisa Cano Navas, El convento de San José del Carmen de Sevilla. Las Teresas. Estudio histórico-artístico, Publicaciones de la Universidad de Sevilla, I984, pp. I44-I 45.

29. Archivo de la Comunidad del Convento de las Teresas de Sevilla, carpeta de donaciones II/f (hoja suelta).

30. En su autobiografía, José María Blanco-White se refiere a ella como la tía Anica, una de las dos hermanas de su padre, exaltando su modernidad por ser la única mujer de Sevilla que poseía una biblioteca propia en su hogar, donde el escritor leyó por primera vez las obras del padre Feijoo. Antonio Garnica (dir.), Autobiografía de Blanco-White, Universidad de Sevilla, 1975, p. 4I. 
que ya se ha señalado es la calidad de la pieza, detrás de la cual no debieron encontrarse un patrono y un receptor cualesquiera. Por otra parte, debe destacarse que la moldura de este lienzo corresponde exactamente con otra pintura de Correa conservada en el convento de San Leandro, por lo que ambas debieron de llegar en fechas cercanas, pudiendo también haber pertenecido a la misma casa. Se debe señalar que en esta clausura se encontraba el hospicio de Indias de los frailes agustinos, renombrados devotos del icono guadalupano, siendo fray Payo de Ribera el máximo representante de la destacada posición que esta orden religiosa alcanzó en las Indias, por lo cual no sería extraño que el citado lienzo proviniese de alguna de las casas agustinas de Sevilla. En sus Antigüedades del convento Casa Grande de San Agustín, Montero de Espinosa señala cómo en la capilla del Nacimiento "se colocó en I724 a nuestra señora de Guadalupe, siendo su patrono el veinticuatro [regidor de ayuntamiento] don Juan Bautista Cavaleri" ${ }^{\text {I }}$ Con independencia de su posible origen o procedencia, dar a conocer este lienzo de la Virgen de Guadalupe supone un aporte significativo a la historiografía sobre Juan Correa, pues queda sobradamente demostrada la maestría del artista como inventor en la configuración de estos tipos iconográficos de la escuela barroca novohispana, adelantándose en su tiempo a las innovaciones de futuras realizaciones. \$\$

31. José Montero de Espinosa, Antigüedades del convento Casa Grande de San Agustín de Sevilla, Sevilla, Imprenta de D. Antonio Carrera, I817, p. I32. 